\title{
Epidermal growth factor receptor tyrosine kinase inhibitors with conventional chemotherapy for the treatment of non-small cell lung cancer
}

This article was published in the following Dove Press journal:

OncoTargets and Therapy

18 December 2015

Number of times this article has been viewed

\author{
Yuan Gaol,* \\ PingPing Song ${ }^{1, *}$ \\ Hui Li' \\ HongBo Guo' \\ Hui Jia ${ }^{2}$ \\ Baijiang Zhang' \\ 'Department of Thoracic Surgery, \\ Shandong Cancer Hospital and \\ Institute, Jinan, Shandong Province, \\ People's Republic of China; \\ ${ }^{2}$ Department of Medical Oncology, \\ Shandong Cancer Hospital and \\ Institute, Jinan, Shandong Province, \\ People's Republic of China \\ *These authors contributed equally \\ to this work
}

\begin{abstract}
We report a Chinese male patient with advanced stage lung squamous cell carcinoma who developed brain metastases after responding to treatment comprising six cycles of conventional chemotherapy with docetaxel and cisplatin. The patient was then treated with oral erlotinib (150 mg/day) and whole-brain radiation therapy followed by four cycles of docetaxel and carboplatin chemotherapy. The patient then received gefitinib $(250 \mathrm{mg} /$ day $)$ as a maintenance therapy until the end of the follow-up period. In this patient, progression-free survival, defined as the interval from the initiation of first-line chemotherapy to the cessation of erlotinib due to progressive disease or death from any cause, was 3 months. Overall survival, defined as the interval from the initiation of first-line chemotherapy to death from any cause, was 75 months. Erlotinib was well tolerated in combination with whole-brain radiation therapy and a favorable objective response rate was observed. Furthermore, targeted drug treatment warrants consideration in patients with a negative epidermal growth factor receptor mutation status and male patients with a history of smoking.
\end{abstract}

Keywords: EGFR tyrosine kinase inhibitors, chemotherapy, non-small cell lung cancer

\section{Introduction}

Lung cancer, of which non-small cell lung cancer (NSCLC) is the most common form, remains the leading cause of cancer-related mortality worldwide, and many NSCLC patients present with advanced disease at the time of initial diagnosis. ${ }^{1}$ Recent advancements in chemotherapy and targeted therapy have provided new treatment options for this disease.

NSCLC research has increasingly focused on efforts to identify biomarkers that can predict increased clinical benefit from new agents in specific patient subgroups to enable clinicians make informed treatment decisions regarding the most appropriate initial treatment option for individual patients. The most promising biomarker to date is the epidermal growth factor receptor (EGFR) mutation status; recent data suggest that compared to patients with tumors lacking such mutations, patients with tumors harboring activating mutations in EGFR achieve a substantially increased benefit from treatment with EGFR tyrosine kinase inhibitors (TKIs). ${ }^{2-7}$ Notably, EGFR mutations occur with greater frequency in Asian patients than in European patients, with typical mutation rates of $\sim 30 \%$ and $8 \%$, respectively. ${ }^{3,8,9}$ Therefore, approximately one in three Asian patients is positive for a biomarker predicting an exceptional response to EGFR TKI therapy. One such EGFR TKI is the orally administered targeted agent erlotinib, which inhibits the tyrosine kinase domain of EGFR. Erlotinib was approved for secondline use based on the positive results of the Phase III BR. 21 trial, ${ }^{10}$ in which erlotinib,
Correspondence: Bailiang Zhang Department of Thoracic Surgery, Shandong Cancer Hospital and Institute, Jiyan Road 440, Jinan, Shandong 250II7, People's Republic of China Email zhangbaijiang@sina.com 
compared with best supportive care, improved overall survival. In Phase II studies, erlotinib has also been shown to have clinical benefit as a first-line therapy for advanced NSCLC, resulting in tumor response rates of $10 \%-20 \%$ and median survival durations of 10.9-12.9 months. ${ }^{11,12}$ However, despite important new additions to the therapeutic arsenal for NSCLC, the 5-year survival rate for patients with this disease remains disappointingly low, at $<20 \% .{ }^{13}$ The implementation of accurate EGFR mutation testing is a key component of biomarker-based treatment strategies in clinical practice; however, thus far, the selection or identification of patients with activating EGFR mutations based on clinical characteristics has been unsatisfactory. ${ }^{2,14}$

Unfortunately, despite treatment advances, the prognosis of patients with advanced lung cancer remains poor, and the vast majority of patients die as a result of uncontrolled systemic disease. Among patients with NSCLC, 20\%-40\% ultimately develop brain metastases. ${ }^{15,16}$ Treatment options for brain metastases from NSCLC include whole-brain radiation therapy (WBRT), stereotactic radiosurgery, surgical resection, or some combination of these three treatments. The median survival duration after WBRT strongly correlates with patient age, Eastern Cooperative Oncology Group performance status, and the number and location of the metastatic lesions, and it generally ranges from 3 to 6 months. ${ }^{17-21}$

The present study describes a 34-year-old male with NSCLC and brain metastases that were incidentally identified during a histopathological examination. This study also includes a review of the relevant literature to provide clinicians with information concerning a novel treatment program for NSCLC that achieved a longer overall survival. Written informed consent was obtained from the patient. The Research Ethics Committee of the Shandong Cancer Hospital and Institute approved this study.

\section{Case report}

A 34-year-old male was admitted to the local hospital in April 2007 complaining of hacking cough of unknown cause. The patient had no symptoms of bosom frowsty, chest pain, anhelation, fever, or weakness, and the patient had not experienced appetite or weight loss. However, the patient showed no evident improvement upon hospitalization. A chest computed tomography (CT) scan in May 2007 at the Affiliated Hospital of Binzhou Medical College (Binzhou, People's Republic of China) revealed a mass in the hilum of the right lung, swollen lymph nodes in the mediastinum, and pleural effusion. Furthermore, fiberoptic bronchoscopy revealed the tumor pathology: moderately differentiated squamous cell carcinoma (SCC) in the middle and lower lobes of the lung. After 3 days, the patient visited the Chinese PLA General Hospital in Beijing, and an abdominal CT scan revealed a suspicious mass, which was considered to be either a metastatic tumor or an adenocarcinoma, in the right adrenal gland. Brain magnetic resonance imaging and bone emission CT showed no evidence of distant metastasis. The patient's medical history was unremarkable, and SCC was staged as T4N2M0 (IIIB) according to the International Union Against Cancer 1997 Tumor Node Metastasis staging criteria. ${ }^{22}$ After several discussions, the oncologists chose not to perform surgery. The patient's alanine aminotransferase level was between 2- and 2.5-fold above normal after admission to the hospital; therefore, treatments to protect the liver were initiated after the patient was admitted. The patient's carcinoembryonic antigen level was $7.6 \mathrm{ng} / \mathrm{mL}$, and carbohydrate antigen 19-9 (CA 19-9) level was $13.4 \mathrm{ng} / \mathrm{mL}$. From May 28, 2007 to September 12, 2007, the patient received six cycles of adjuvant chemotherapy consisting of $300 \mathrm{mg}$ of paclitaxel and $750 \mathrm{mg}$ of dicycloplatin on day 1 of each 2 -week cycle. The evident side effects of this adjuvant chemotherapy regimen were myelosuppression with grade 0-2 neutrocytopaenia and a grade 1 gastrointestinal reaction. The patient demonstrated a partial response (PR) after four cycles and complete response (CR) after six cycles according to the chest CT scan, which showed a streaky or coarse reticular pattern of opacities in the upper right lobe under the pleura and small nodules in the right hilum (Figure 1). The patient did not receive any additional therapy until February 18,2008 , when a chest CT scan demonstrated lung cancer with mediastinal lymph node metastasis, a right lower lobe lesion $(4.4 \times 3.1 \mathrm{~cm})$, and mediastinal lymph node enlargement. Brain CT showed abnormal enhancement in the right occipital lobe with evidence of metastatic disease. Abdominal ultrasound revealed medium-low echo in the right adrenal gland nodules and did not rule out adrenal metastasis. These findings indicated local recurrence and brain metastases. Therefore, from February 26, 2008 to June 14, 2008, the patient underwent six additional cycles of chemotherapy for progressive disease (PD) according to the following medication schedule: 1,000 $\mathrm{mg}$ of pemetrexed disodium on day 1 ; $50 \mathrm{mg}$ of cisplatin on days 1 and 2; and $40 \mathrm{mg}$ of cisplatin on day 3 . This cycle was repeated every 2 weeks. For the first 12 cycles, $140 \mathrm{mg}$ of cisplatin was administered on day 1 . Grade 0-1 myelosuppression and grade 0-1 gastrointestinal reactions were observed. A potential PR was assessed after cycle 8 , and the patient was evaluated after cycle 10 

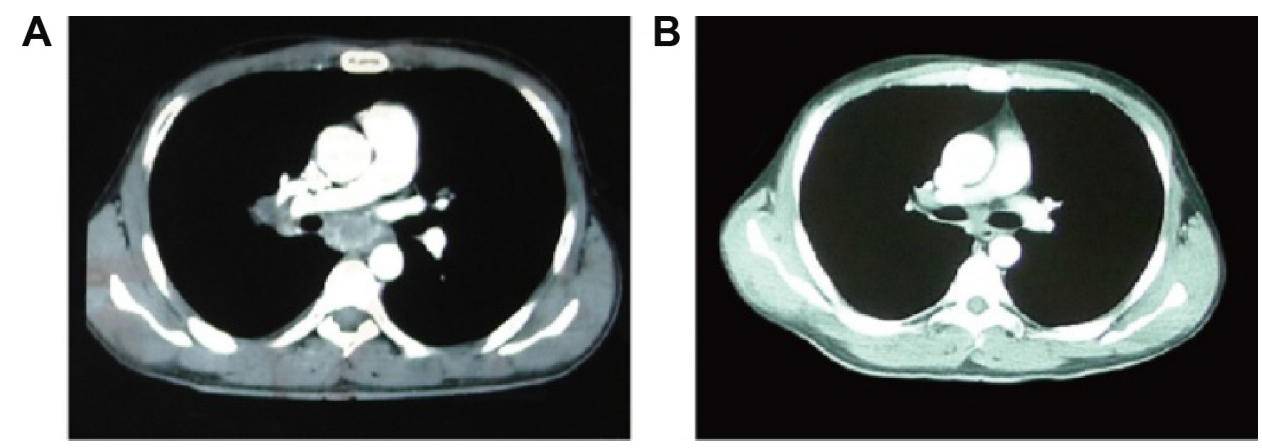

Figure I A complete response after six cycles of chemotherapy according to the contrast-enhanced chest computed tomography scan.

Notes: Contrast-enhanced chest computed tomography scan showing a mass located in the hilum of the right lung (A). This mass exhibited evident shrinkage following six cycles of chemotherapy (B).

for stable disease (SD) (Figure 2). Beginning on March 7 , 2008 , sequential adjuvant radiotherapy was performed via $40 \mathrm{~Gy} / 20 \mathrm{~F}$ irradiation of the whole brain and $60 \mathrm{~Gy} / 20 \mathrm{~F}$ irradiation of the right occipital metastasis; no side effects were observed after the six cycles of maintenance radiotherapy. Oral erlotinib (150 mg/day) was administered from July 2008 to December 2009 (Figure 3). At the scheduled follow-up on December 7, 2009, the abdominal CT scan showed liver and adrenal metastases. On December 11, 2009 , a brain magnetic resonance imaging scan revealed abnormal enhancement in the nodules of the right occipital lobe (ovular shape with a diameter of $\sim 12 \mathrm{~cm}$ ) with a history of suspected metastases, a right cerebellar lesion without abnormal enhancement, and a lesion with a slight increase in contrast compared with that of the original film. Emission CT showed no signs of bone metastases (Figure 4). From December 11, 2009 to January 3, 2010, the patient underwent retreatment according to chemotherapy cycles 1 and 2 using the following medications: $140 \mathrm{mg}$ of docetaxel intravenously (iv) on day 1 and $500 \mathrm{mg}$ of carboplatin iv on day 1 . The patient experienced grade 0-2 side effects, bone marrow suppression, gastrointestinal reactions, nausea and vomiting. On January 22, 2010, an abdominal CT scan revealed multiple liver lesions (potential metastatic disease) and right adrenal metastases $(4.6 \times 3.7 \mathrm{~cm})$. On December 7, 2009, a focused abdominal CT with contrast was performed to evaluate the patient for a PR. From January 23, 2010 to February 20, 2010, the patient was re-treated according to chemotherapy cycles 3 and 4 using the following medications: $140 \mathrm{mg}$ of docetaxel iv on day 1 and $500 \mathrm{mg}$ of carboplatin iv on day 1 (Figure 5). The patient experienced bone marrow suppression, grade $0-2$ side effects, gastrointestinal reactions, nausea, and vomiting. Oral gefitinib treatment was initiated in June 2010 and continued until the patient died of pulmonary infection and cachexia in August 2013 (Figure 6).

\section{Discussion}

Erlotinib was initially used in combination with chemotherapy as a first-line treatment for advanced NSCLC but was found to be ineffective. ${ }^{23,24}$ This lack of efficacy could be explained by the hypothesis that a negative interaction occurs between EGFR TKIs and cytotoxic agents when they are administered concurrently and by the fact that no molecular biomarkers exist to identify appropriate patients for this combination treatment. Subsequently, several randomized studies, including the BR.21 and TRUST studies,
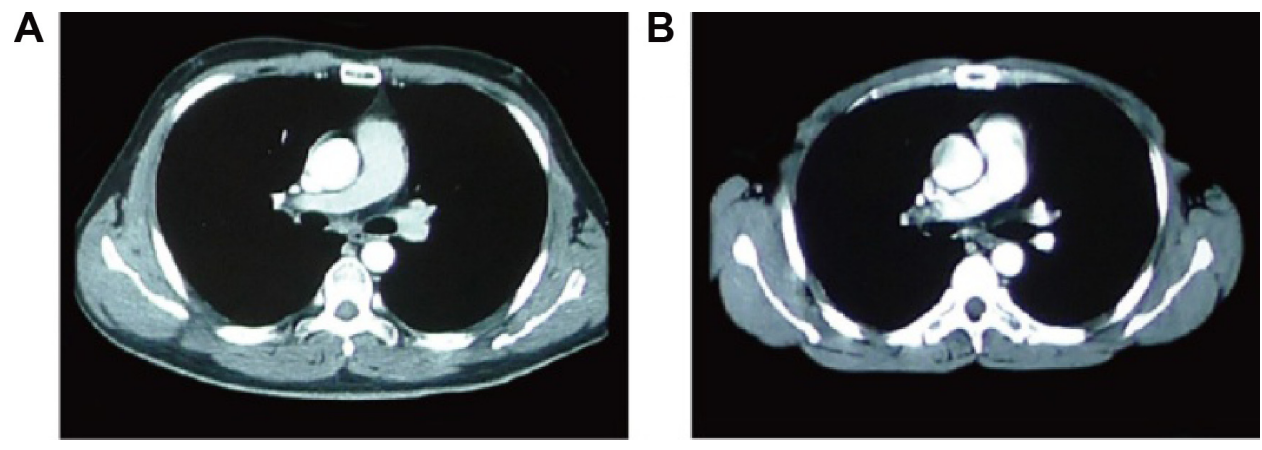

Figure 2 A stable disease after six additional cycles of chemotherapy according to the contrast-enhanced chest computed tomography scan.

Notes: Enhanced chest computed tomography scan on February 18, 2008, showing lung cancer with mediastinal lymph node metastasis, a right lower lobe lesion, and mediastinal lymph node enlargement $(\mathbf{A})$. The lesion was significantly reduced and remained stable after six additional cycles of chemotherapy (B). 

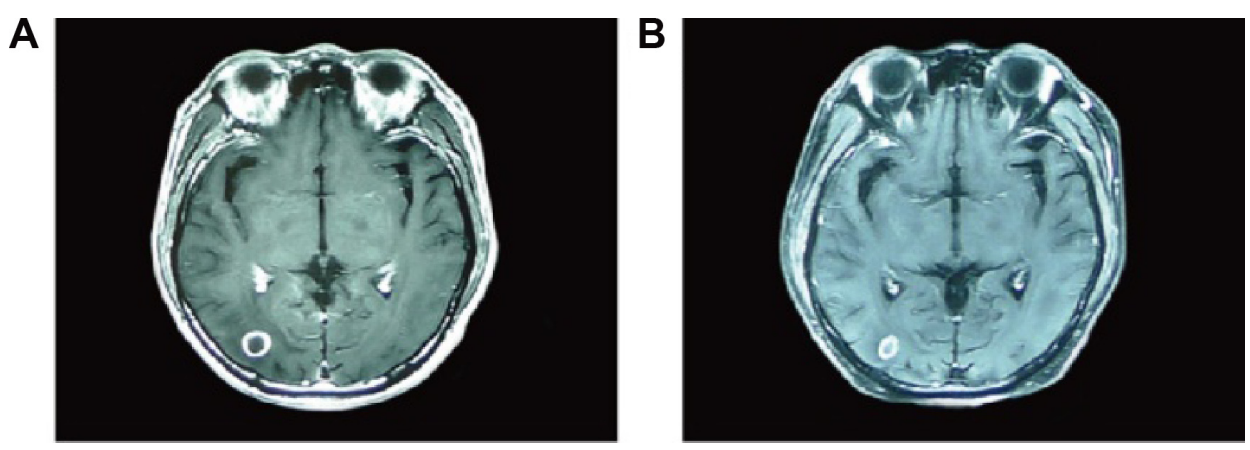

Figure 3 Enhanced brain computed tomography scan showing that erlotinib treatment combined with whole-brain radiation therapy was effective for the patient. Notes: Enhanced brain computed tomography scan revealing metastasis in the right occipital lobe (A). This metastasis significantly shrank after erlotinib treatment combined with whole-brain radiation therapy until September 2009 (B).

have demonstrated the promising efficacy of erlotinib as a second-line or third-line treatment for patients with advanced NSCLC. ${ }^{10,25}$ As shown in the Iressa Pan-Asia Study (IPASS), a multicenter, Phase III, randomized study that examined the combination of gefitinib, carboplatin and paclitaxel as a firstline treatment for clinically selected patients in East Asia, ${ }^{2}$ EGFR-mutant lung cancer patients form a distinct subgroup exhibiting a superior clinical outcome in response to EGFR TKI treatment. Subsequently, two Japanese trials comparing first-line gefitinib therapy with chemotherapy for exclusively
EGFR-mutant lung cancers confirmed the conclusion of the IPASS. ${ }^{5,6}$ However, no related studies on sequential intercalated combination regimens of chemotherapy and erlotinib have been reported. Importantly, activating EGFR mutations was found in only $30 \%-40 \%$ of Chinese patients with adenocarcinoma, and EGFR mutation testing was performed in only $10 \%$ of these patients; thus, the EGFR mutation status is unknown in most Chinese patients when decisions are made regarding the first-line treatment regimen. ${ }^{26}$ For these patients, a combination of chemotherapy and EGFR TKIs
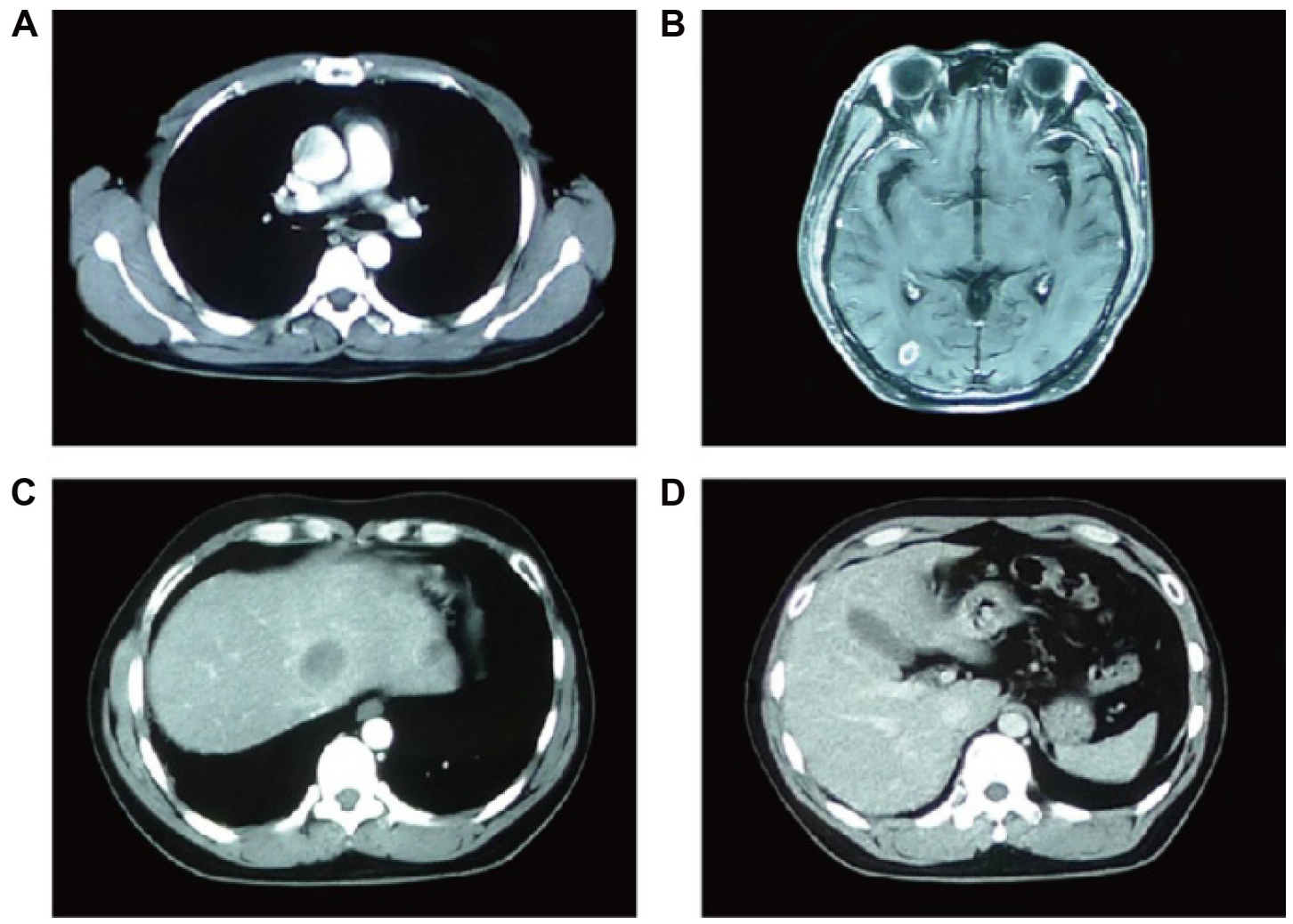

Figure 4 Abdominal computed tomography scan showed liver and adrenal metastases, and other lesions did not change significantly.

Notes: Enhanced abdominal computed tomography scan showing liver and adrenal metastases (A, D). A brain magnetic resonance image revealed abnormal enhancement in nodules of the right occipital lobe with a history of suspected metastases and a right cerebellar lesion without abnormal enhancement (B). An enhanced chest computed tomography scan showed no significant change compared to the original film (C). 
A

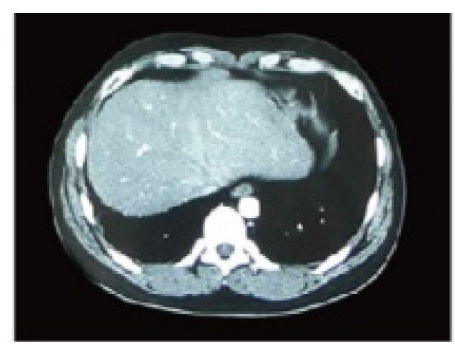

B

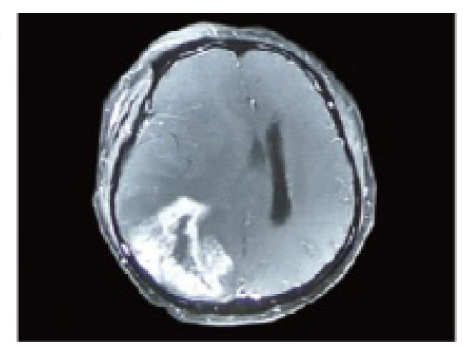

C

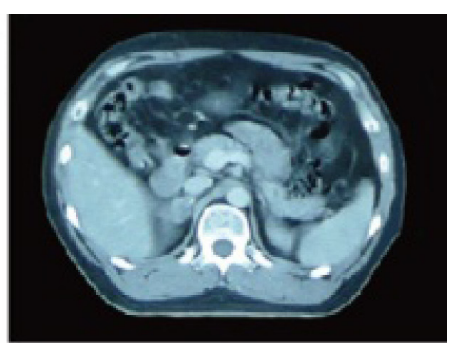

Figure $5 \mathrm{~A}$ brain magnetic resonance image and an enhanced abdominal computed tomography showed no significant change from the previous month. Notes: An enhanced abdominal computed tomography scan revealing multiple liver lesions and right adrenal metastases (A, $\mathbf{C})$. A brain magnetic resonance image showed no significant change from the previous month (B).

might be optimal. Although previous Phase III studies in unselected populations showed that the combination of chemotherapy and erlotinib did not improve survival compared with chemotherapy alone, ${ }^{23,24}$ sequential intercalated combination regimens of chemotherapy and erlotinib (the First-line Asian Sequential Tarceva and Chemotherapy Trial) significantly improved response and progression-free survival rates, especially in patients with adenocarcinoma. ${ }^{27}$

Our patient with untreated stage IIIB NSCLC received six cycles of paclitaxel and dicycloplatin. During the subsequent follow-up, the patient attained disease control, defined as a $\mathrm{CR}$ or a PR according to the response evaluation criteria in solid tumors (RECIST). ${ }^{28}$ Pemetrexed disodium and cisplatin therapy was administered after the confirmation of PD according to the RECIST guidelines. ${ }^{28}$ This regimen was supplemented with WBRT and shrinking field cranial irradiation. Maintenance therapy with erlotinib was initiated immediately after attaining disease control using the appropriate traditional first-line chemotherapy. In the subsequent follow-up period, the emergence of new metastases and significant growth of the primary lesion indicated PD according to the RECIST guidelines. ${ }^{28}$ At that time, the patient was treated with traditional docetaxel and carboplatin chemotherapy. Thus, a sequential intercalated combination regimen of chemotherapy and erlotinib is a treatment option for patients with advanced NSCLC. When a patient experiences rapid
NSCLC progression, such as PD according to the RECIST guidelines, ${ }^{28}$ we recommend first-line chemotherapy. When a patient is stable (CR, PR, or SD according to the RECIST guidelines ${ }^{28}$ ) or is experiencing slow progression (some cases of PD), we propose that erlotinib maintenance therapy should be administered.

Most studies of EGFR TKIs have focused on patients with specific characteristics (eg, sex, smoking status, and histology) and activating EGFR mutations. Therefore, many studies have focused on patients with characteristics associated with the presence of activating EGFR mutations, especially those patients with histological evidence of adenocarcinoma. We did not perform EGFR mutation testing in this study because the majority of each biopsy specimen was used for pathologic testing and because of the associated cost and patient intolerance of this testing. However, some patients with lung SCC derive a clinical benefit from EGFR TKIs. In 2006, Achille et al reported a case of a white male former smoker with advanced lung SCC who responded to erlotinib. ${ }^{29}$ No EGFR mutations were found in that patient's tumor tissue. The frequency of EGFR mutations is much lower in lung SCC patients and is reported to be between $0 \%$ and $5 \%{ }^{30-34}$ The largest lung SCC study to date was conducted by Miyamae et al; ${ }^{31}$ EGFR mutations were detected in $3.4 \%$ of the 87 lung SCC specimens by using SmartAmp2 and peptide nucleic acid-enriched sequencing methods. The
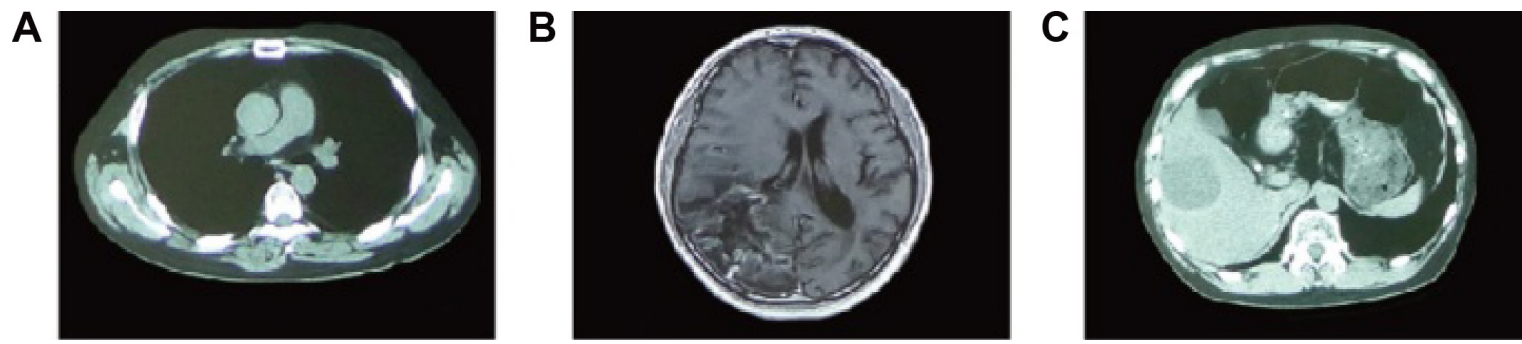

Figure 6 Imaging findings after the patient received maintenance therapy with oral gefitinib.

Notes: A brain magnetic resonance image and an enhanced abdominal computed tomography scan shown in a stable disease (B, C). An enhanced chest computed tomography scan showed no significant change compared to the original film (A). 
current case did not appear to meet any of the suggested criteria for EGFR TKI therapy. EGFR mutation is a powerful predictor of the treatment response to EGFR TKIs. ${ }^{2,3,35-38}$ In the BR. 21 study, ${ }^{39}$ patients harboring an EGFR mutation had a $23 \%$ reduced risk of death following erlotinib treatment compared with placebo (hazard ratio [HR]: 0.77). As stated in the review by Sun et al, $25 \%$ of lung cancers are not attributable to smoking, and a high proportion of Asian women are never-smokers but still develop lung cancer. ${ }^{39}$ In the Japanese cohort examined by Kawaguchi et al, $36.2 \%$ of the female lung SCC patients were never-smokers $(n=991) .{ }^{40}$ Several risk factors such as environmental tobacco smoke, cooking oil vapors, and wood or coal burning are associated with lung cancer in never-smokers, and exposure to these risk factors is also common among Chinese men. Due to the retrospective nature of the present study, evaluating whether these factors contributed to our patient's disease is difficult. ${ }^{41,42}$

Although the mechanisms by which gefitinib and erlotinib inhibit EGFR function are similar, whether they possess comparative efficacy as a salvage therapy for NSCLC remains controversial. ${ }^{43}$ A series of case studies reported objective responses or SD in certain patients who received erlotinib after failing treatment with gefitinib for advanced NSCLC. ${ }^{44-47}$ However, two Phase II studies of erlotinib in such patients reported overall response rates of only 4\%-10\%. ${ }^{48,49}$ Erlotinib exhibited remarkable efficacy in combination with chemotherapy in NSCLC patients with brain metastases. ${ }^{49-51}$ EGFR TKIs exhibit excellent penetration of the blood-brain barrier because of their chemical structure and low molecular weight. In 2003, Cappuzzo et $\mathrm{al}^{49}$ first reported one CR and three PRs after 3 months of single-agent gefitinib treatment in four NSCLC patients with pretreated brain metastases. Furthermore, a multi-institutional Phase II study demonstrated that the overall survival of patients receiving WBRT with concurrent erlotinib therapy for the treatment of NSCLC was longer than that observed in historical controls and that this therapy particularly benefitted patients with EGFR mutations. ${ }^{21}$ Moreover, in our case, a significantly different response to gefitinib therapy was observed after attaining SD in response to erlotinib therapy and chemotherapy. However, we could not ascertain the mechanisms underlying the effectiveness of gefitinib in this case. In vitro studies indicated that the common mechanisms underlying TKI resistance (T790M and mesenchymal to epithelial transition factor [MET] amplification) were not inhibited by clinically achievable doses of gefitinib or erlotinib. ${ }^{52,53}$ Secondary T790M mutation and MET amplification have been commonly described as the mechanisms underlying acquired resistance to EGFR
TKIs. ${ }^{52,53}$ If tumor progression occurs in patients with erlotinib-responsive NSCLC harboring EGFR mutations, the tumor cells have a high probability of becoming crossresistant to gefitinib. However, other secondary mutations such as L747S and E884K have also been described; these mutations may result in differential responses to gefitinib and erlotinib. ${ }^{54}$ According to experimental studies, some irreversible and second-generation EGFR inhibitors can overcome the resistance induced by secondary T790M mutations. ${ }^{52,55,56}$ Currently, irreversible EGFR inhibitors and anti-MET therapeutics are being developed for the treatment of NSCLC. The results of clinical trials will determine whether these agents can be used to treat patients with acquired resistance to EGFR TKIs. ${ }^{57,58}$

\section{Conclusion}

For patients with advanced NSCLC, sequential intercalated combination regimens of chemotherapy and erlotinib could be considered. An assessment of concurrent erlotinib and radiation therapy for the initial treatment of brain metastases from NSCLC demonstrated that this combination was safe and well tolerated. However, these findings must be interpreted cautiously because they were only observed in one case and because a randomized, controlled trial has yet to be performed. Larger prospective, randomized clinical trials are needed to validate our findings and confirm these hypotheses.

\section{Acknowledgment}

This work was partly supported by the Shandong Province Natural Science Foundation of China, as a part of the items outlined in Project No ZR211HM089.

\section{Disclosure}

The authors report no conflicts of interest in this work.

\section{References}

1. Ferlay J, Shin HR, Bray F, Forman D, Mathers C, Parkin DM. Estimates of worldwide burden of cancer in 2008: GLOBOCAN 2008. Int J Cancer. 2010;127:2893-2917.

2. Mok TS, Wu YL, Thongprasert S, et al. Gefitinib or carboplatin-paclitaxel in pulmonary adenocarcinoma. $N$ Engl J Med. 2009;361:947-957.

3. Rosell R, Moran T, Queralt C, et al. Screening for epidermal growth factor receptor mutations in lung cancer. N Engl J Med. 2009;361:958-967.

4. Zhu CQ, da Cunha Santos G, Ding K, et al. Role of KRAS and EGFR as biomarkers of response to erlotinib in National Cancer Institute of Canada Clinical Trials Group Study BR.21. J Clin Oncol. 2008;26: 4268-4275.

5. Mitsudomi T, Morita S, Yatabe Y, et al. Gefitinib versus cisplatin plus docetaxel in patients with non-small-cell lung cancer harbouring mutations of the epidermal growth factor receptor (WJTOG3405): an open label, randomised phase 3 trial. Lancet Oncol. 2010;11:121-128. 
6. Maemondo M, Inoue A, Kobayashi K, et al. Gefitinib or chemotherapy for non-small-cell lung cancer with mutated EGFR. $N$ Engl J Med. 2010;362:2380-2388.

7. Cappuzzo F, Ciuleanu T, Stelmakh L, et al. Erlotinib as maintenance treatment in advanced non-small-cell lung cancer: a multicentre, randomised, placebo-controlled phase 3 study. Lancet Oncol. 2010;11:521-529.

8. Shigematsu H, Lin L, Takahashi T, et al. Clinical and biological features associated with epidermal growth factor receptor gene mutations in lung cancers. J Natl Cancer Inst. 2005;97:339-346.

9. Wu YL, Zhong WZ, Li LY, et al. Epidermal growth factor receptor mutations and their correlation with gefitinib therapy in patients with non-small cell lung cancer: a meta-analysis based on updated individual patient data from six medical centers in mainland China. $J$ Thorac Oncol. 2007;2:430-439.

10. Shepherd FA, Rodrigues Pereira J, Ciuleanu T, et al. Erlotinib in previously treated non-small-cell lung cancer. $N$ Engl J Med. 2005; 353:123-132.

11. Giaccone G, Gallegos Ruiz M, Le Chevalier T, et al. Erlotinib for frontline treatment of advanced non-small cell lung cancer: a phase II study. Clin Cancer Res. 2006;12:6049-6055.

12. Jackman DM, Yeap BY, Lindeman NI, et al. Phase II clinical trial of chemotherapy-naive patients $>$ or $=70$ years of age treated with erlotinib for advanced non-small-cell lung cancer. J Clin Oncol. 2007;25:760-766.

13. Jemal A, Siegel R, Xu J, Ward E. Cancer statistics, 2010. CA Cancer J Clin. 2010;60:277-300.

14. Lind JS, Postmus PE, Heideman DA, Thunnissen EB, Bekers O, Smit EF. Dramatic response to low-dose erlotinib of epidermal growth factor receptor mutation-positive recurrent non-small cell lung cancer after severe cutaneous toxicity. J Thorac Oncol. 2009;4:1585-1586.

15. Mujoomdar A, Austin JH, Malhotra R, et al. Clinical predictors of metastatic disease to the brain from non-small cell lung carcinoma: primary tumor size, cell type, and lymph node metastases. Radiology. 2007;242:882-888.

16. Barnholtz-Sloan JS, Sloan AE, Davis FG, Vigneau FD, Lai P, Sawaya RE. Incidence proportions of brain metastases in patients diagnosed (1973 to 2001) in the Metropolitan Detroit Cancer Surveillance System. J Clin Oncol. 2004;22:2865-2872.

17. Verger E, Gil M, Yaya R, et al. Temozolomide and concomitant whole brain radiotherapy in patients with brain metastases: a phase II randomized trial. Int J Radiat Oncol Biol Phys. 2005;61:185-191.

18. Sperduto PW, Berkey B, Gaspar LE, Mehta M, Curran W. A new prognostic index and comparison to three other indices for patients with brain metastases: an analysis of 1,960 patients in the RTOG database. Int J Radiat Oncol Biol Phys. 2008;70:510-514

19. Gaspar L, Scott C, Rotman M, et al. Recursive partitioning analysis (RPA) of prognostic factors in three Radiation Therapy Oncology Group (RTOG) brain metastases trials. Int J Radiat Oncol Biol Phys. 1997;37:745-751.

20. Knisely JP, Berkey B, Chakravarti A, et al. A phase III study of conventional radiation therapy plus thalidomide versus conventional radiation therapy for multiple brain metastases (RTOG 0118). Int J Radiat Oncol Biol Phys. 2008;71:79-86.

21. McHaffie DR, Chabot P, Dagnault A, et al. Safety and feasibility of motexafin gadolinium administration with whole brain radiation therapy and stereotactic radiosurgery boost in the treatment of $\leq 6$ brain metastases: a multi-institutional phase II trial. J Neurooncol. 2011; 105:301-308.

22. Mountain CF. Revisions in the international system for staging lung cancer. Chest. 1997;111:1710-1717.

23. Herbst RS, Prager D, Hermann R, et al. TRIBUTE: a phase III trial of erlotinib hydrochloride (OSI-774) combined with carboplatin and paclitaxel chemotherapy in advanced non-small-cell lung cancer. J Clin Oncol. 2005;23:5892-5899.

24. Gatzemeier U, Pluzanska A, Szczesna A, et al. Phase III study of erlotinib in combination with cisplatin and gemcitabine in advanced non-small-cell lung cancer: the Tarceva Lung Cancer Investigation Trial. J Clin Oncol. 2007;25:1545-1552.
25. Reck M, van Zandwijk N, Gridelli C, et al. Erlotinib in advanced non-small cell lung cancer: efficacy and safety findings of the global phase IV Tarceva Lung Cancer Survival Treatment study. J Thorac Oncol. 2010;5:1616-1622.

26. Xue $\mathrm{C}, \mathrm{Hu} Z$, Jiang W, et al. National survey of the medical treatment status for non-small cell lung cancer (NSCLC) in China. Lung Cancer. 2012;77:371-375

27. Heymach JV, Johnson BE, Prager D, et al. Randomized, placebo-controlled phase II study of vandetanib plus docetaxel in previously treated non small-cell lung cancer. J Clin Oncol. 2007;25:4270-4277.

28. Goldie JH, Coldman AJ. A mathematic model for relating the drug sensitivity of tumors to their spontaneous mutation rate. Cancer Treat Rep. 1979;63:1727-1733.

29. Achille M, Gallegos-Ruiz M, Giaccone G, Soria JC. Response to erlotinib in first-line treatment of non-small-cell lung cancer in a white male smoker with squamous-cell histology. Clin Lung Cancer. 2006; $8: 214-216$.

30. Huang SF, Liu HP, Li LH, et al. High frequency of epidermal growth factor receptor mutations with complex patterns in non-small cell lung cancers related to gefitinib responsiveness in Taiwan. Clin Cancer Res. 2004;10:8195-8203.

31. Miyamae Y, Shimizu K, Hirato J, et al. Significance of epidermal growth factor receptor gene mutations in squamous cell lung carcinoma. Oncol Rep. 2011;25:921-928.

32. Mu XL, Li LY, Zhang XT, et al. Gefitinib-sensitive mutations of the epidermal growth factor receptor tyrosine kinase domain in Chinese patients with non-small cell lung cancer. Clin Cancer Res. 2005;11: 4289-4294.

33. Ohtsuka K, Ohnishi H, Fujiwara M, et al. Abnormalities of epidermal growth factor receptor in lung squamous-cell carcinomas, adenosquamous carcinomas, and large-cell carcinomas: tyrosine kinase domain mutations are not rare in tumors with an adenocarcinoma component. Cancer. 2007;109:741-750.

34. Qin BM, Chen X, Zhu JD, Pei DQ. Identification of EGFR kinase domain mutations among lung cancer patients in China: implication for targeted cancer therapy. Cell Res. 2005;15:212-217.

35. Lynch TJ, Bell DW, Sordella R, et al. Activating mutations in the epidermal growth factor receptor underlying responsiveness of non-small-cell lung cancer to gefitinib. N Engl J Med. 2004;350:2129-2139.

36. Paez JG, Janne PA, Lee JC, et al. EGFR mutations in lung cancer: correlation with clinical response to gefitinib therapy. Science. 2004; 304:1497-1500.

37. Pao W, Miller V, Zakowski M, et al. EGF receptor gene mutations are common in lung cancers from "never smokers" and are associated with sensitivity of tumors to gefitinib and erlotinib. Proc the Natl Acad Sci US A. 2004;101:13306-13311.

38. Rosell R, Viteri S, Molina MA, Benlloch S, Taron M. Epidermal growth factor receptor tyrosine kinase inhibitors as first-line treatment in advanced nonsmall-cell lung cancer. Curr Opin Oncol. 2010;22: $112-120$.

39. Sun S, Schiller JH, Gazdar AF. Lung cancer in never smokers - a different disease. Nat Rev Cancer. 2007;7:778-790.

40. Zhao Y, Wang S, Aunan K, Seip HM, Hao J. Air pollution and lung cancer risks in China - a meta-analysis. Sci Total Environ. 2006;366: $500-513$.

41. Kawaguchi T, Takada M, Kubo A, et al. Performance status and smoking status are independent favorable prognostic factors for survival in non-small cell lung cancer: a comprehensive analysis of 26,957 patients with NSCLC. J Thorac Oncol. 2010;5:620-630.

42. Shao YY, Lin CC, Yang CH. Gefitinib or erlotinib in the treatment of advanced non-small cell lung cancer. Discov Med. 2010;9:538-545.

43. Kaira K, Naito T, Takahashi T, et al. Pooled analysis of the reports of erlotinib after failure of gefitinib for non-small cell lung cancer. Lung Cancer. 2010;68:99-104.

44. Zhou ZT, Xu XH, Wei Q, Lu MQ, Wang J, Wen CH. Erlotinib in advanced non-small-cell lung cancer after gefitinib failure. Cancer Chemother Pharmacol. 2009;64:1123-1127. 
45. Wong AS, Soong R, Seah SB, et al. Evidence for disease control with erlotinib after gefitinib failure in typical gefitinib-sensitive Asian patients with non-small cell lung cancer. J Thorac Oncol. 2008;3: 400-404.

46. Vasile E, Tibaldi C, Chella A, Falcone A. Erlotinib after failure of gefitinib in patients with advanced non-small cell lung cancer previously responding to gefitinib. J Thorac Oncol. 2008;3:912-914.

47. Cho BC, Im CK, Park MS, et al. Phase II study of erlotinib in advanced non-small-cell lung cancer after failure of gefitinib. J Clin Oncol. 2007;25:2528-2533.

48. Lee DH, Kim SW, Suh C, Yoon DH, Yi EJ, Lee JS. Phase II study of erlotinib as a salvage treatment for non-small-cell lung cancer patients after failure of gefitinib treatment. Ann Oncol. 2008;19:2039-2042.

49. Cappuzzo F, Ardizzoni A, Soto-Parra H, et al. Epidermal growth factor receptor targeted therapy by ZD 1839 (Iressa) in patients with brain metastases from non-small cell lung cancer (NSCLC). Lung Cancer. 2003;41:227-231

50. Hotta K, Kiura K, Ueoka H, et al. Effect of gefitinib ('Iressa', ZD1839) on brain metastases in patients with advanced non-small-cell lung cancer. Lung Cancer. 2004;46:255-261.

51. Ishida A, Kanoh K, Nishisaka T, et al. Gefitinib as a first line of therapy in non-small cell lung cancer with brain metastases. Intern Med. 2004; 43:718-720.

52. Kobayashi S, Boggon TJ, Dayaram T, et al. EGFR mutation and resistance of non-small-cell lung cancer to gefitinib. $N$ Engl J Med. 2005; $352: 786-792$
53. Bean J, Brennan C, Shih JY, et al. MET amplification occurs with or without T790M mutations in EGFR mutant lung tumors with acquired resistance to gefitinib or erlotinib. Proc Natl Acad Sci US A. 2007;104: 20932-20937.

54. Costa DB, Halmos B, Kumar A, et al. BIM mediates EGFR tyrosine kinase inhibitor-induced apoptosis in lung cancers with oncogenic EGFR mutations. PLoS Med. 2007;4:1669-1679.

55. Costa DB, Son K, Cho BC, et al. Effects of erlotinib in EGFR mutated non-small cell lung cancers with resistance to gefitinib. Clin Cancer Res. 2008;14:7060-7067.

56. Kwak EL, Sordella R, Bell DW, et al. Irreversible inhibitors of the EGF receptor may circumvent acquired resistance to gefitinib. Proc Natl Acad Sci U S A. 2005;102:7665-7670.

57. Gonzales AJ, Hook KE, Althaus IW, et al. Antitumor activity and pharmacokinetic properties of PF-00299804, a second-generation irreversible pan-erbB receptor tyrosine kinase inhibitor. Mol Cancer Ther. 2008;7:1880-1889.

58. Eskens FA, Mom CH, Planting AS, et al. A phase I dose escalation study of BIBW2992, an irreversible dual inhibitor of epidermal growth factor receptor 1 (EGFR) and 2 (HER2) tyrosine kinase in a 2-week on, 2-week off schedule in patients with advanced solid tumours. Br J Cancer. 2008;98:80-85.
OncoTargets and Therapy

\section{Publish your work in this journal}

OncoTargets and Therapy is an international, peer-reviewed, open access journal focusing on the pathological basis of all cancers, potential targets for therapy and treatment protocols employed to improve the management of cancer patients. The journal also focuses on the impact of management programs and new therapeutic agents and protocols on

\section{Dovepress}

patient perspectives such as quality of life, adherence and satisfaction. The manuscript management system is completely online and includes a very quick and fair peer-review system, which is all easy to use. Visit http://www.dovepress.com/testimonials.php to read real quotes from published authors. 